\title{
Effects of Laryngeal Massage on Muscle Tension Dysphonia: A Systematic Review and Meta-Analysis
}

\author{
Jaeock Kim iD \\ Division of Speech Pathology Education, Graduate School of Education, Kangnam University, Yongin, Korea
}

근긴장성 발성장애의 후두마사지 효과: 체계적 고찰 및 메타분석

김재옥

강남대학교 교육대학원 언어치료교육

Background and Objectives This study was to investigate the voice quality and articulation effects of laryngeal massage on muscle tension dysphonia (MTD).

Materials and Method A systematic review of articles published between January 2000 and December 2020 in Cochrane, PubMed, ScienceDirect, SpingerLink, ERIC, and Naver Academic was conducted. From the total of 2094 articles identified, 10 peer-reviewed articles were included in a meta-analysis. Mean effect sizes of the variables related to voice quality (jitter, shimmer, harmonic to noise ratio or noise to harmonic ratio, high-FO, low-l, cepstral peak prominence) and articulation (F1, F2, F1 slope, F2 slope) were calculated by Hedges'g.

Results Meta-analysis of the selected articles showed that laryngeal massage had medium to large effects on all variables of voice quality and articulation except F0-high and F1 slope in the MTD patients.

Conclusion This study provided comprehensive clinical evidence that it is highly desirable to apply laryngeal massage to MTD patients.

Keywords Meta-analysis; Laryngeal massage; Muscle tension dysphonia; Voice quality; Articulation.

\section{서 론}

근긴장성 발성장애(muscle tension dysphonia, MTD)는 후두 주변근의 과도한 긴장 으로 인해 후두의 위치가 상승하고 성대의 진동이 원활하지 못하게 되는 기능적 음성장 애(functional dysphonia)이다. MTD 환자의 주된 증상은 목의 조임이나 피로감, 통증, 긴장되고 쥐어 짜는 음성, 기식 음성, 쉰 목소리, 음역대 감소 등의 음질 저하가 나타나 며, 공명이나 조음에도 영향을 받아 조음이 부정확할 수 있다[1-5].

선행연구들에 의하면 MTD 환자에게 간접 및 직접 음성치료가 효과적이다[2,3,5]. 간 접치료는 음성위생과 음성 오·남용 예방을 위한 교육을 의미하며, 직접치료는 후두의 위치 교정, 내·외후두근의 이완, 호흡훈련, 효율적인 성대 접촉, 공명 및 조음 향상 훈련
Received February 27, 2021

Revised March 18, 2021

Accepted March 25, 2021

\section{Corresponding Author}

Jaeock Kim, PhD

Division of Speech Pathology Education,

Graduate School of Education,

Kangnam University,

40 Gangnam-ro, Giheung-gu,

Yongin 16979, Korea

Tel +82-31-280-3221

Fax $+82-31-280-3479$

E-mail jaeock@gmail.com

\section{ORCID iD}

Jaeock Kim (iD

https://orcid.org/0000-0002-6504-7294

This is an Open Access article distributed under the terms of the Creative Commons Attribution Non-Commercial License (https://creativecommons.org/ licenses/by-nc/4.0) which permits unrestricted non-commercial use, distribution, and reproduction in any medium, provided the original work is properly cited. 
등이 포함된다. 이 중에서도 MTD 환자의 과도하게 긴장된 후두와 목 주변근을 이완시켜 발성과 조음 능력을 향상시킬 수 있는 후두마사지가 일차적으로 적용될 수 있다[1-8].

후두마사지는 manual circumlaryngeal therapy (MCT), laryngeal manual therapy (LMT)[8], cricovisor maneuver (CVM)[3], voice massage[9] 등으로 다양하다. 이들은 일부 방법적인 면에서 조금씩 차이가 있으며, MCT가 임상에서 일 반적으로 많이 사용된다.

MTD 환자에게 적용한 후두마사지의 효과를 객관적 근거 로 제시한 연구들이 다수 있는데, 일부 연구에서는 기초선이 다른 MTD 환자와 일반인 간의 중재 효과의 차이를 제시하 였거나[7], 사례연구 또는 단일대상 연구와 같이 매우 소수의 대상에게 중재를 실시하여[10,11] 후두마사지의 효과를 일반 화하기 어려운 경우도 있다. 또한 후두마사지와 다른 중재를 함께 실시함으로써 후두마사지만의 중재 효과를 파악하기 어 려운 연구들도 있다[12].

최근 MTD 환자에게 실시한 후두마사지의 효과를 일반화 하고자 하는 노력으로 메타분석을 실시한 연구가 있다[6]. 이 연구에서는 후두마사지의 효과를 청지각적 평가와 대상자가 경험하는 음성증상이나 통증과 같은 주관적 평가만을 분석 하였고, Likert 척도나 시각적 아날로그 수치로 제시된 결과를 효과가 '있다 또는 없다의 명목형 응답으로 변형하여 분석하 였다. 분석에 포함된 대상 연구는 3편에 불과하여 후두마사지 의 효과를 객관적으로 일반화하는 데 다소 무리가 있다. 이 에 후두마사지가 MTD 환자의 음성이나 조음에 미치는 영향 을 객관적으로 평가한 연구들을 종합적으로 고찰하여 중재의 효과를 일반화할 수 있는지 살펴볼 필요가 있다.

본 연구는 후두마사지가 MTD 환자의 음질과 조음에 미치 는 영향을 음향학적 평가로 분석한 선행연구들을 체계적으 로 고찰하고, 메타분석을 통해 중재의 효과크기를 종합적으 로 분석하고자 한다.

\section{대상 및 방법}

\section{연구 설계}

본 연구는 후두마사지가 MTD 환자의 음질과 조음에 미치 는 영향을 체계적이고 종합적으로 분석하기 위한 메타분석 연구이다.

\section{대상 연구 선정 기준}

본 연구는 체계적인 문헌고찰을 통해 메타분석에 사용될 대상 연구를 선정하고자 population, intervention, comparison, outcome, study designs (PICOS) 기준에 따라 문헌을 검
색하였다. 연구대상(P)은 구조적 또는 신경학적 병변이 없는 원발성(primary) MTD나 과기능적 음성장애로 진단받은 18세 이상 성인으로 하였고, 중재 방법(I)은 후두마사지로 $\mathrm{MCT}$, $\mathrm{LMT}$ 또는 CVM을 단독으로 실시한 경우로 제한하였다. 비 교집단(C)은 후두마사지를 실시하지 않은 집단을 대조군으로 하였고, 단일집단에서 사전-사후 측정이 이루어진 경우도 포 함하였다. 중재결과 $(\mathrm{O})$ 는 음질이나 조음을 평가하기 위한 음 향학적 평가로 제한하였다. 연구 설계(S)는 집단 간 사전-사후 를 비교한 무작위대조실험(randomized controlled trial, RCT), 준실험설계(quasi-experimental design) 그리고 집단 내 사 전-사후를 비교한 단일집단전후비교(one group pre-post design)로 한정하였다. 서로 다른 연구 설계도 하나의 메타분 석에서 효과크기(effect size)를 계산할 수 있기 때문에[13] 본 연구에서도 집단 간 사전-사후비교연구와 집단 내 사전-사후 비교연구를 모두 분석대상에 포함하였다. 본 선정 기준에 부 합하지 않는 연구는 배제하였고, 평균, 표준편차, 중위수, 사 분위수, 표본수, t값 등의 효과크기 변환이 가능한 통계치를 제시한 문헌들을 분석대상으로 선정하였다.

\section{문헌 검색 및 선정}

MTD 환자에게 후두마사지를 실시하고 음질과 조음을 분 석한 문헌을 살펴보기 위해 국내 1개(네이버 학술정보)와 국 외 5개(Cochrane, PubMed, ScienceDirect, SpingerLink, $\mathrm{ERIC})$ 의 데이터베이스를 검색하였다. 검색에 포함된 기간은 2000년 1월 1일에서 2020년 12월 31일까지로 하였고, Medical Subject Headings (MeSH) 용어와 주제어(keyword)는 "hyperfunctional voice" OR "muscle tension dysphonia" OR "dysphonia" AND "manual" OR "massage" OR "laryngeal massage" OR "laryngeal manual therapy"로 하였으며, 동료 심사(peer review)에 의해 학술지에 게재된 연구로 제한하였다. 각 데이터베이스를 통해 검색된 총 논문 편수는 2094편으 로, Cochrane이 18편, PubMed가 103편, ScienceDirect가 1413편, SpingerLink가 377편, ERIC이 35편, 네이버 학술정 보가 148 편이었다. 이들의 제목과 초록을 분석하여 중복된 논 문(1212편)을 제외한 882편 중에서 본 연구와 관련이 없는 논문(800편), 영어나 한국어 이외의 언어로 작성된 논문(36편), 정상 음성, 가수 또는 아동을 대상으로 한 논문(12편), 2개 이 상의 복합 중재나 후두마사지 이외의 다른 중재 논문(4편), 리 뷰 논문(6편)을 제외한 24편의 연구를 선별하여 전문(full text) 이용이 가능한 논문들을 살펴보았다. 제1평가자가 선정한 24편의 논문들을 대상으로 음성장애 치료와 교육 경력이 10 년 이상인 언어병리학 박사 1 명이 선정기준에 따라 독립적으 로 평가하였다. 이에 최종적으로 성대의 병변이 있는 속발성 
MTD (secondary MTD)를 대상으로 한 논문(6편), 후두마사 지 외 중재 방법(5편), 단일대상 연구(3편)를 제외한 10 편의 논문을 분석대상으로 선정하였다. 이 중 1편의 논문[7]은 대 조군이 정상 음성 산출자였고, 2편[1,14]은 대조군에서 다른 치료를 적용하였기에 이들은 대조군을 제외한 실험군의 결과 만을 사용하였다. 본 메타분석의 대상 논문을 선정하는 과정 과 포함 및 제외 기준은 Fig. 1 과 같다.

최종 선정된 10편의 논문[1-5,7,8,14-16]에서 1편은 MCT를 실시한 집단과 $\mathrm{MCT}$ 와 $\mathrm{CVM}$ 을 함께 실시한 집단으로 나뉘어 있고[3], 다른 1편은 성별을 따로 구분하여 중재 결과를 산출 하였으며[4], 다른 2편은 중재결과를 각기 다른 두 과제에서 측정하였기에 총 14 편으로 구분하여 분석하였다[7,8].

중재결과는 음질과 조음을 평가하는 음향학적 평가로 음질 은 jitter, shimmer, harmonic to noise ratio (HNR) 또는 noise to harmonic ratio (NHR), high F0 (F0-high), low intensity (I-low), dysphonic severity index (DSI), cepstral peak prominence (CPPs)였고, 조음은 F1, F2, F1 slope 및 F2 slope를 포함하였다. 중재결과는 중재가 종료된 시점에서 측정된 결 과값을 사용하였고, 시간 경과에 따른 측정치는 분석에 포 함하지 않았다.

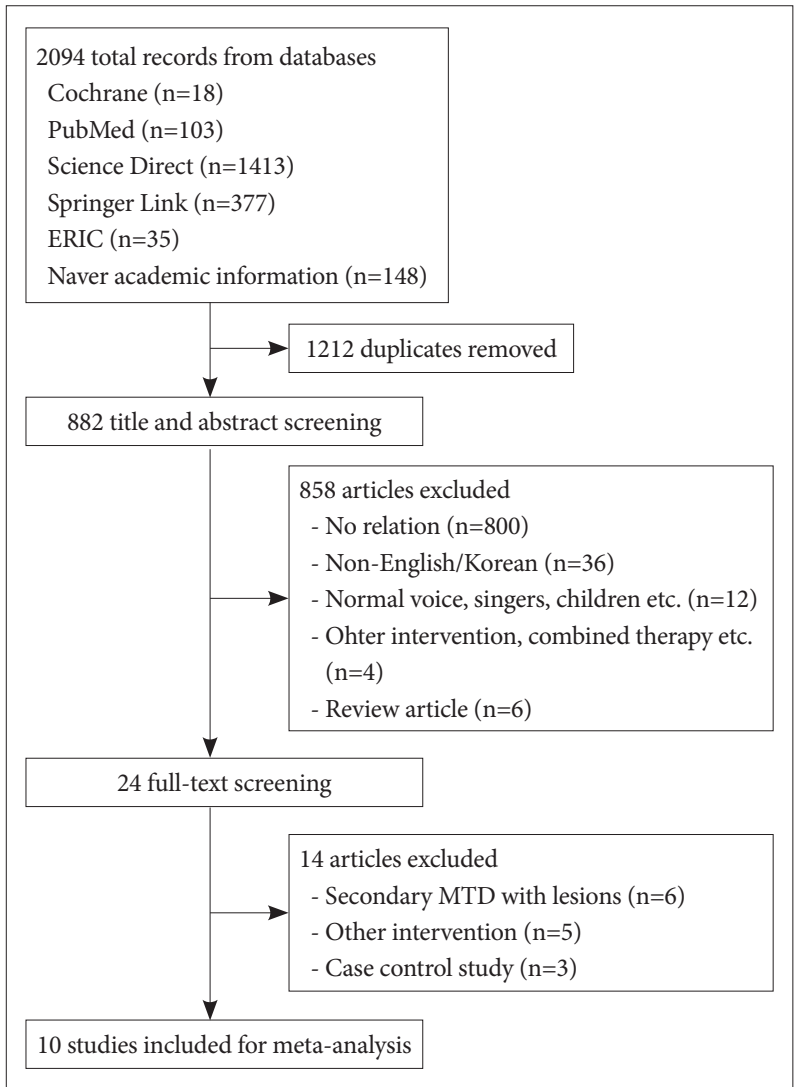

Fig. 1. Flow of information through the different phases of a systematic review. MTD, muscle tension dysphonia.

\section{분석대상 연구의 질 평가}

본 연구는 RCT 연구뿐 아니라 비무작위연구(non-randomized study), 즉 준실험설계와 단일집단전후비교연구를 포함하기 때문에 비무작위연구의 질 평가를 위해 개발된 Slim 등[17]의 Methodological Index for Non-Randomized Studies (MINORS)를 이용하여 선정된 논문 10편의 질적 평 가를 실시하였다.

MINORS에서 비교대상이 없는 비무작위연구는 1-8번까 지의 8개 공통 항목으로 평가하고, 대조군이 있는 연구는 912 번까지의 4 개 항목을 추가적으로 평가한다. 평가항목은 1) 연구 목적의 명확성, 2) 대상자 선정의 적합성, 3) 전향적 자료 수집, 4) 연구목적에 적합한 연구결과 도출, 5) 연구결과의 비 뚤림(bias) 없는 평가, 6) 연구목적에 부합한 추적기간, 7) $5 \%$ 미만의 탈락률, 8) 대상자 수의 전향적 계산, 9) 적절한 대조 군, 10) 집단의 동시 모집, 11) 집단 간 동일한 기초선, 12) 적절 한 통계 분석의 내용으로 구성되어 있다. 각 항목은 3점 척도 (0점 보고되지 않음, 1점 보고는 되었으나 부적절, 2점 보고되 었고 적절함)로 평가하고, 총점수는 비무작위연구의 경우 16 점, 대조군이 있는 연구는 총 24점이 만점이다. 본 연구에 포 함된 논문들의 질 평가 결과, 모든 논문에서 1-4번, 6번 및 7 번 항목들이 모두 2점으로 평가되었으나 5번 항목에서 3편 $[1,4,8]$ 의 논문이 연구결과에 사용된 변수들을 반복측정하지 않았거나 주관적인 평가의 경우 신뢰도 검정을 실시하지 않 아 0 점 또는 1점으로 평가되었다. 또한 8 번 항목은 1 편의 논 문을 제외한 모든 연구에서 연구대상자의 수를 전향적으로 계산하지 않아 0 점으로 평가받았다. 이에 논문 10 편의 질 평 가를 실시한 결과, 비무작위연구인 8편의 평균점수는 13.38 (12-14)점, 대조군이 있는 2편의 평균점수는 23 (22-24)점으로 분석대상 모두 만점은 아니지만 질적으로 적절하다고 판단하 였다. 각 논문의 질적 평가 결과는 Table 1 에 제시하였다.

\section{자료 코딩}

선정된 연구들은 연구자, 출판년도, 대상자 수, 독립변인(후 두마사지), 중재 횟수 및 기간, 종속변인(음질, 조음)에 따라 코 딩하였다. 각 종속변인은 개별 연구의 평균 $(\overline{\mathrm{X}})$ 과 표준편차 $(\mathrm{S})$ 를 입력하였고, 평균만 제시된 경우는 평균의 사전-사후 차이 에 대한 t 또는 F 통계량과 유의확률(p)을 사용하였으며, 중 위수, 최소값, 최대값이 제시된 경우는 Wan 등[18]이 제시한 공 식(Fig. 2)을 이용하여 평균과 표준편차로 변환하였다.

\section{자료 분석}

자료는 Comprehensive Meta-Analysis 3 version 3.3.070 (CM3; Biostat Inc., Englewood, NJ, USA)으로 분석하였다. 


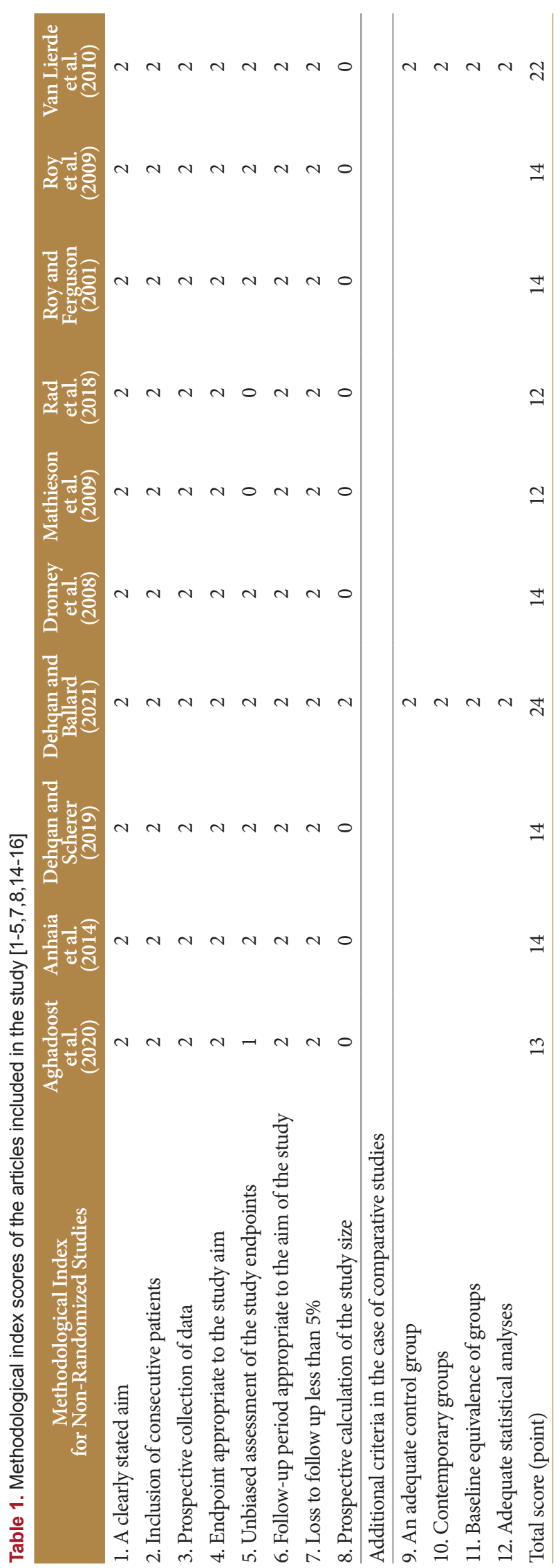

$$
\begin{aligned}
& \overline{\mathrm{X}} \approx \frac{\mathrm{a}+2 \mathrm{~m}+\mathrm{b}}{4}+\frac{\mathrm{a}-2 \mathrm{~m}+\mathrm{b}}{4 \mathrm{n}} \\
& \mathrm{S} \approx \frac{\mathrm{b}-\mathrm{a}}{\xi(\mathrm{n})} \\
& \overline{\mathrm{X}}=\text { mean, } \mathrm{S}=\text { standard deviation } \\
& \mathrm{a}=\text { minimun value, } \mathrm{b}=\text { maximum value, } \mathrm{m}=\text { median }
\end{aligned}
$$

Fig. 2. Formula to convert median to mean value.

모든 연구결과에 대한 효과크기는 다수의 연구에서 표본 수 가 많지 않다는 점을 고려하여 표준화된 평균 차이를 통해 산출된 Cohen's d를 표본 크기에 따라 가중치를 두어 교정한 Hedges' g와 95\% 신뢰수준(confidence interval, CI)을 산출 하였고, 유의수준 0.05 를 기준으로 효과크기의 유의성을 검정 하였다. 일반적으로 효과크기가 0-0.32이면 작은 크기, 0.330.55 이면 중간 크기, 0.56 이상이면 큰 크기라고 할 수 있다[19]. 또한 평균효과크기는 각 연구마다 연구방법, 표본 크기, 중재 방법 등이 서로 다르다는 점을 고려하여 무선효과모형(random effects model)을 적용하였다[19].

개별효과크기 간의 통계적 이질성(heterogeneity)은 forest plot을 통해 시각적으로 살펴본 후에, 동질성 검증(test of heterogeneity)을 위해 각 효과크기들의 관찰된 분산인 Q값을 산출하여 $\chi^{2}$ 검정을 실시하였고, 연구 간 분산의 비율인 $\mathrm{I}^{2}$ 값 을 산출하였다. 일반적으로 동질성 검증의 $\mathrm{p}$ 값이 0.10 보다 작 고 $\mathrm{I}^{2}$ 이 $50 \%$ 이상인 경우 효과크기의 이질성은 큰 것으로 해 석한다[20].

또한 본 연구에서 분석된 연구들의 출판편향(publication bias)을 분석하기 위해 funnel plot으로 시각적 좌우대칭성을 검토하였고, Egger의 회귀분석을 실시하여 통계적 대칭성을 분석하였다.

\section{결 과}

\section{분석대상 연구의 질적 분석}

본 연구에서 분석대상으로 선정한 10편의 연구논문을 대 상자, 중재 방법 및 측정 과제에 따라 14편으로 구분하여 분 석한 결과를 Supplementary Table 1 (in the online-only Data Supplement)에 제시하였다. 분석대상 논문의 출판년도는 2001년에서 2020년까지 고루 분포되어 있었다.

연구대상자는 총 500 명의 후두 병변이 없는 원발성 MTD (12편)와 과기능적 음성장애(2편) 환자로 각 논문별 최소 8명 에서 최대 130 명이며, 20명 이하인 경우가 7편, 21-30명인 경 우가 3편, 31명 이상인 경우가 4편이었다. 중재 방법은 후두마 사지로 13 편이 $\mathrm{MCT}$ 를 사용하였고, 2편에서는 $\mathrm{MCT}+\mathrm{CVM}$ 과 
LMT를 각각 적용하였다. 후두마사지를 실시한 횟수는 1회기 를 실시한 논문이 12 편, 10 회기와 15 회기를 실시한 논문이 각 1 편씩이었다. 한 회기당 평균 중재 시간은 약 26.3 분으로 범 위가 5-45분이었고, 7편의 논문에서는 중재 시간을 제시하지 않았다. 후두마사지의 중재결과인 음질의 음향학적 분석은 jitter가 8편, shimmer가 7편, HNR 또는 NHR이 6편, F0high, I-low, DSI 및 CPPs가 각 2편에서 사용되었다. 조음의 음향학적 분석은 F1이 6편, F2가 3편, F1 slope과 F2 slope 이 각 2편씩에서 분석되었다. 또한 비교집단으로 후두마사지 를 실시하지 않은 대조군이 포함된 연구가 3편으로, 이 중 1편 은 동일 집단을 실험군과 대조군으로 하였고, 나머지 11편은 단일집단에서 중재 전과 후를 비교하였다.

\section{후두마사지의 효과크기}

본 연구의 분석대상인 14편을 대상으로 교정된 표준화된 평균 차이인 Hedges' $\mathrm{g}(\mathrm{g})$ 로 평균효과크기를 산출한 결과는 forest plot으로 제시하였다(Figs. 3 and 4). 전체 논문의 평균 효과크기 $g=-0.15$ (95\% CI: -0.33-0.03)로 통계적으로 유의 하지 않았다.

후두마사지가 MTD의 음질에 미치는 효과도 $\mathrm{g}=-0.02(95 \%$ CI: -0.28-0.25)로 통계적으로 유의하지 않았다(Fig. 3A). 그 러나 음질의 각 하위 변수별 평균효과크기는 Table 2 와 Fig. $3 \mathrm{~B}-\mathrm{H}$ 에 제시한 바와 같이 jitter는 $\mathrm{g}=-0.58$ (95\% CI: $-0.85-$ -0.31 ), shimmer는 $g=-0.39$ (95\% CI: $-0.69--0.09)$, I-low는 $\mathrm{g}=-1.07$ (95\% CI: -1.67- -0.47)로 나타나 세 변수 모두 중간 에서 큰 정도의 효과크기를 보이며 통계적으로 유의하게 낮 아진 반면, $\mathrm{HNR}$ (NHR은 효과크기의 방향을 $\mathrm{HNR}$ 과 동일하 게 $[+]$ 로 설정)은 $\mathrm{g}=0.60$ (95\% CI: 0.22-0.98), DSI는 $\mathrm{g}=2.03$ (95\% CI: 1.23-2.83), CPPs는 g=0.77 (95\% CI: 0.01-1.53)의 매 우 큰 정도의 효과크기를 가지며 유의하게 높아졌다. 즉 F0high를 제외한 모든 음질 하위변수에서 음질이 향상되는 방 향의 유의한 효과크기가 나타났다.

또한 후두마사지가 $\mathrm{MTD}$ 의 조음에 미치는 평균효과크기는 $\mathrm{g}=-0.37$ (95\% CI: -0.64- -0.10)로 나타나 중간 정도의 효과크 기를 보이며 통계적으로 유의하였다(Fig. 4A). 조음의 각 하 위 변수별 평균효과크기를 살펴보면, F1은 g=-0.71 (95\% CI: $-1.17--0.26), \mathrm{F} 2$ 는 $\mathrm{g}=-0.80$ (95\% CI: $-1.31--0.28$ )으로 큰 정 도의 효과크기로 유의하게 낮아졌고, F2 slope은 $\mathrm{g}=0.37$ (95\% CI: 0.23-0.50)로 중간 정도의 효과크기를 보이면서 유의하게 높아졌다(Table 2 and Fig. 4B, C, and E). 그러나 F1 slope은 통계적으로 유의한 효과크기가 나타나지 않았다(Fig. 4D).

\section{효과크기의 이질성 검증}

각 연구에서 산출된 효과크기 간의 차이를 살펴보기 위해 Fig. $3 \mathrm{~A}$ 와 Fig. $4 \mathrm{~A}$ 의 forest plot을 보면 $\mathrm{g}$ 가 다양하게 분포되 어 있다. 또한 효과크기의 동질성 검증을 통해 산출된 전체 효 과크기의 이질성이 매우 컸고 $\left(\mathrm{I}^{2}=87.49 \%, \mathrm{Q}=327.62, \mathrm{p}<0.001\right)$, 음질은 $\mathrm{I}^{2}$ 이 $84.30 \%(\mathrm{Q}=178.36, \mathrm{p}<0.001)$, 조음은 $\mathrm{I}^{2}$ 이 $91.96 \%$ $(\mathrm{Q}=149.28, \mathrm{p}<0.001)$ 로 음질과 조음에 대한 개별 연구의 효 과크기 간의 이질성은 상당히 크게 나타났다. 각 연구 간 효 과크기의 이질성은 개별 연구 간의 대상자 수의 차이, 중재 횟 수나 기간의 차이, 연구설계 유형의 차이 등 다양한 연구 배경 에서 기인하였다고 볼 수 있다.

\section{출판편향 분석}

본 연구의 분석대상 논문들의 출판편향을 살펴본 결과, funnel plot에서 시각적 대칭성이 관찰되었고(Fig. 5), Egger 의 회기분석 실시 결과, bias $=-0.96$ ( $\mathrm{t}=0.40, \mathrm{df}=40, \mathrm{p}=0.254$ )로 출판편향이 없음을 알 수 있다.

\section{고 찰}

본 연구는 MTD 환자에게 적용한 후두마사지가 음질과 조 음에 미치는 효과를 종합적으로 분석하고자 체계적인 문헌고 찰을 통한 메타분석을 실시하였다. 2000년에서 2020년까지 $\mathrm{MTD}$ 와 후두마사지를 키워드로 하여 국문 또는 영문으로 게재된 국내외 논문들을 고찰하고, 선정기준에 따라 총 10 편 의 논문을 선정하였으며, 대상자, 중재 방법 및 측정 과제에 따 라 14 편으로 구분하여 분석하였다.

14 편의 연구대상자는 총 500명으로 원발성 MTD와 병변이 없는 과기능적 음성장애 환자였고, 각 논문에 따라 대상자의 수가 8명에서 130명으로 다양하였다. 중재 방법은 후두마사 지로 여러 기법 중 $\mathrm{MCT}$ 를 1 회 적용한 연구가 가장 많았다. 중 재 결과로 가장 많이 분석된 변수는 음질 평가에서 jitter와 shimmer였고, 조음 평가에서는 F1이었다. 그 외 변수로는 음 질 평가로 HNR (NHR), F0-high, I-low, DSI, CPPs와 조음 평가는 F2, F1 slope 및 F2 slope가 사용되었다.

본 연구의 분석대상인 14 편 논문의 전체 평균효과크기 $(\mathrm{g}=$ $-0.15)$ 와 음질의 평균효과크기 $(\mathrm{g}=-0.02)$ 는 통계적으로 유의 하지 않았으나 조음의 평균효과크기 $(\mathrm{g}=-0.37)$ 는 유의하였다. 전체 변수들을 종합하여 분석할 경우 각 하위 변수들의 개별 적 특성에 따른 효과크기 방향(+ 또는 -)의 차이로 인해 평균 효과크기가 유의하지 않을 수 있다. 이에 음질과 조음별로 하 위 변수들의 평균효과크기를 살펴본 결과, 음질에서는 F0high를 제외한 모든 하위 변수들과 조음에서도 F1 slope을 


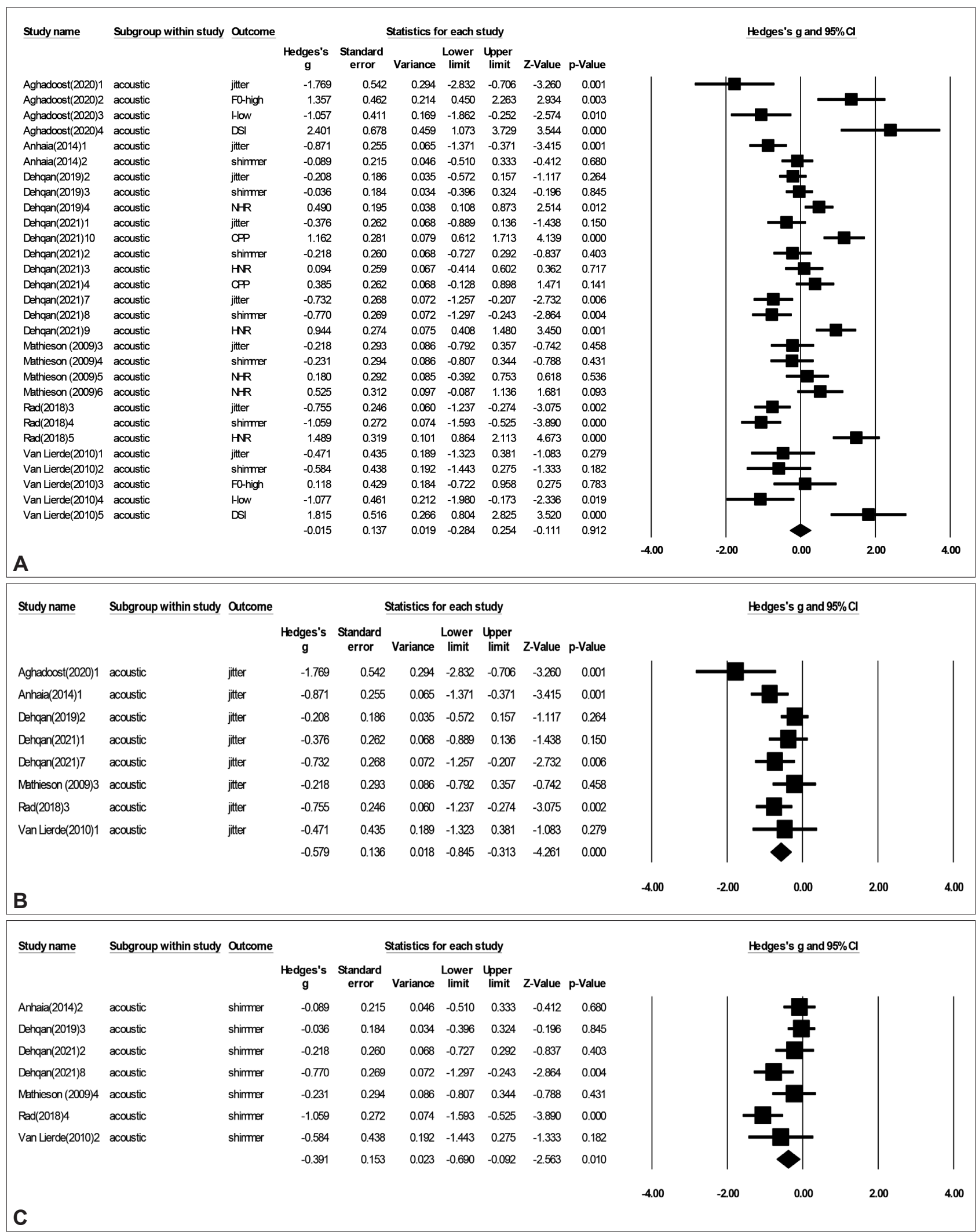

Fig. 3. Forest plots of the effects of laryngeal massage on voice quality of MTD patients (random effect model) [1-4,8,14,16]. A: The effect of laryngeal massage on voice quality. B: The effect of laryngeal massage on jitter. C: The effect of laryngeal massage on shimmer. F0-high, high F0; I-low, low intensity; DSI, dysphonic severity index; NHR, noise to harmonic ratio; CPP, cepstral peak prominence; HNR, harmonic to noise ratio; $\mathrm{Cl}$, confidence interval. 
제외한 모든 하위 변수들이 유의한 효과크기가 나타났다.

음질을 평가한 논문들을 개별적으로 살펴보면, 일부는[1,2] 후두마사지를 실시한 후 음질이 향상되었으나 다른 논문[1,3,
8,14,16]은 후두마사지 실시 전과 후에 유의한 차이가 없어 연 구마다 상반된 결과들을 보여 후두마사지의 효과를 객관적 으로 파악하는 데 한계가 있다. 그러나 본 메타분석 연구를 통

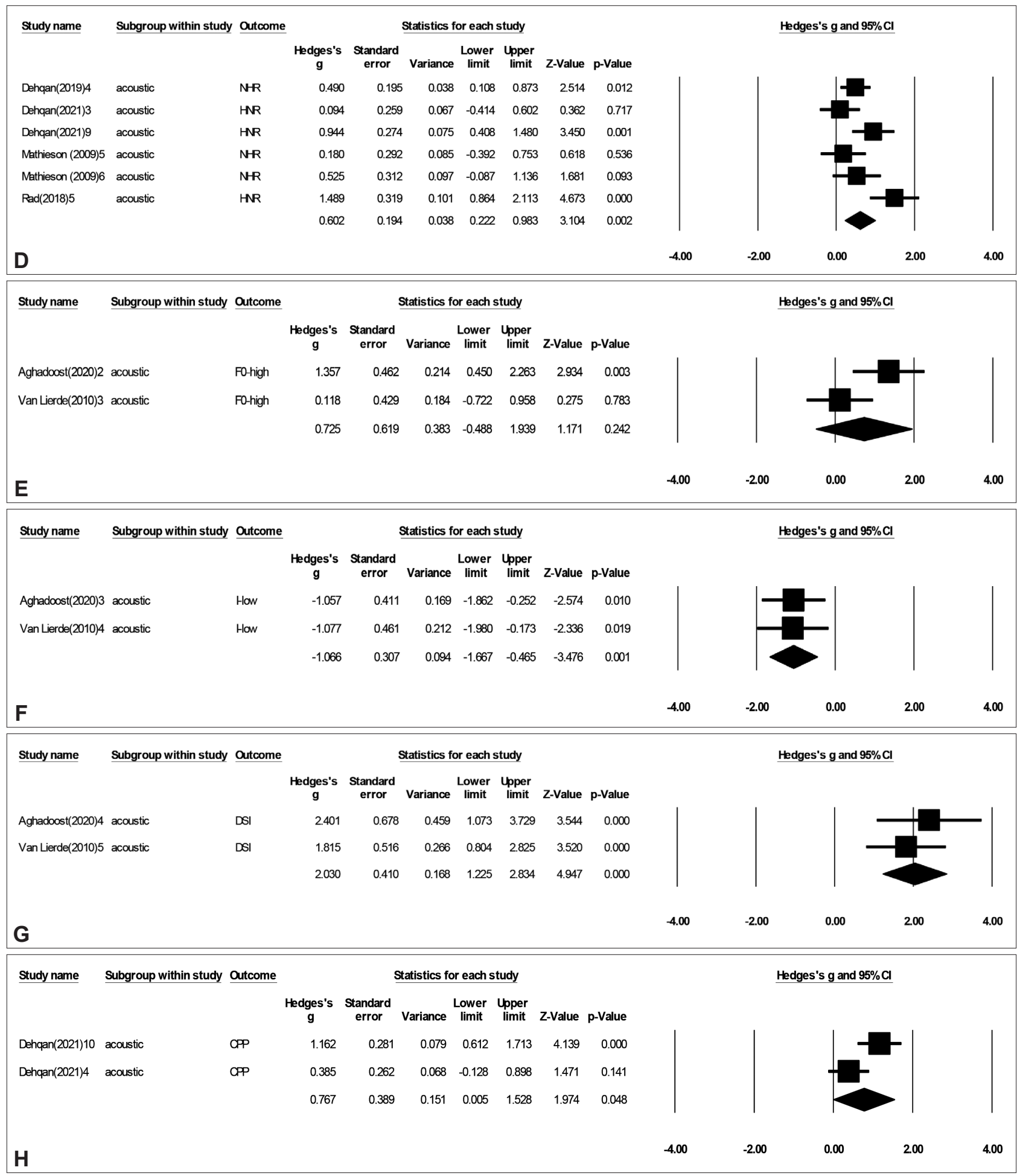

Fig. 3. Forest plots of the effects of laryngeal massage on voice quality of MTD patients (random effect model) [1-4,8,16]. D: The effect of laryngeal massage on HNR (NHR). E: The effect of laryngeal massage on F0-high. F: The effect of laryngeal massage on I-low. G: The effect of laryngeal massage on DSI. $\mathrm{H}$ : The effect of laryngeal massage on CPPs (continued). NHR, noise to harmonic ratio; HNR, harmonic to noise ratio; $\mathrm{Cl}$, confidence interval; F0-high, high F0; I-low, low intensity; DSI, dysphonic severity index; CPP: cepstral peak prominence. 


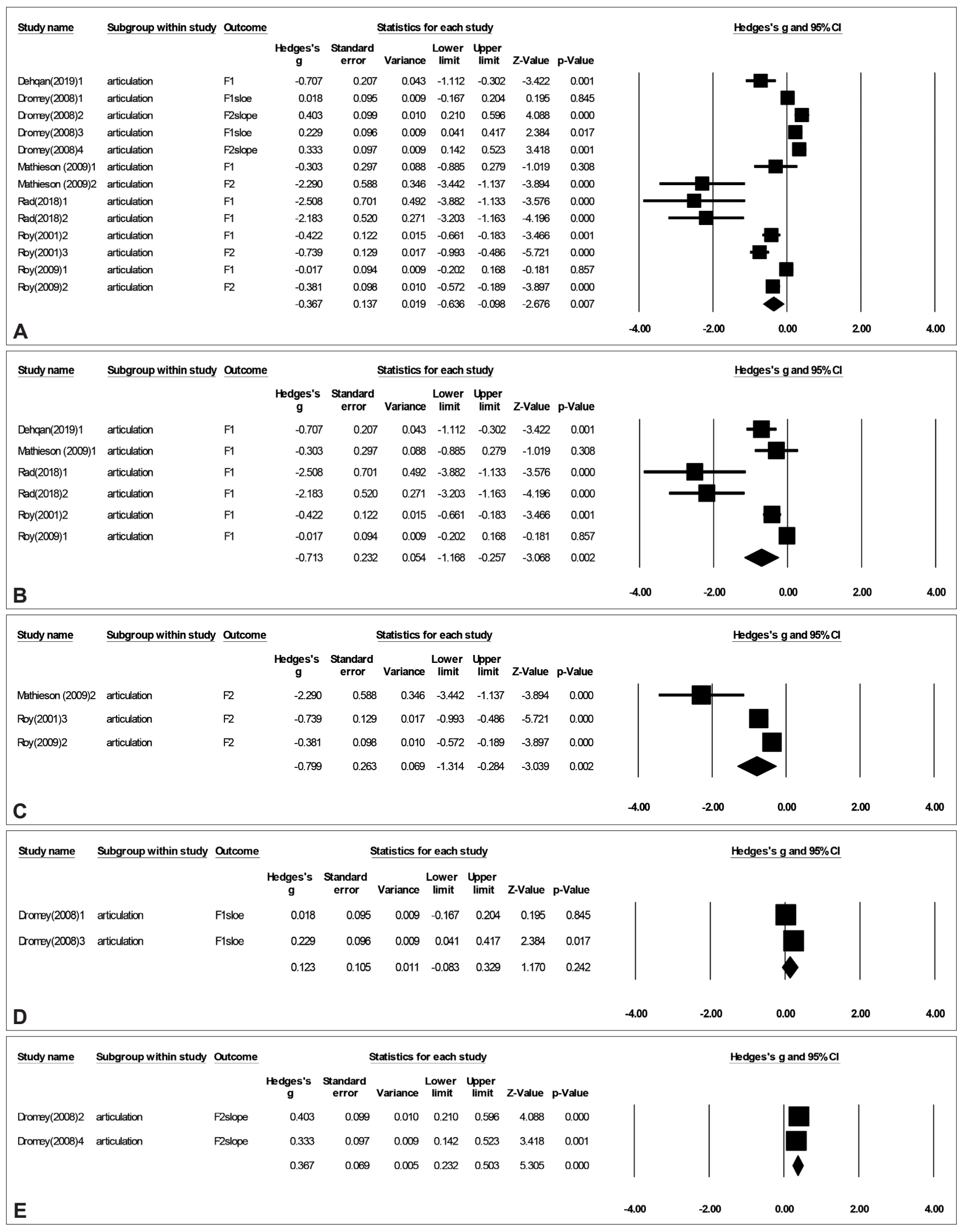

Fig. 4. Forest plots of the effects of laryngeal massage on articulation of MTD patients (random effect model) $[2,4,5,7,8,15]$. A: The effect of laryngeal massage on articulation. B: The effect of laryngeal massage on F1. C: The effect of laryngeal massage on F2. D: The effect of laryngeal massage on F1 slope. E: The effect of laryngeal massage on F2 slope. F1 and F2, first and second form; Cl, confidence interval. 
해 개별 연구들을 체계적이고 종합적으로 분석한 결과, jitter $(\mathrm{g}=-0.58)$, shimmer $(\mathrm{g}=-0.39), \mathrm{I}-\mathrm{low}(\mathrm{g}=-1.07)$ 는 중간에서 큰 정도의 효과크기를 보이면서 유의하게 감소하였고, HNR (NHR, $\mathrm{g}=0.60), \mathrm{DSI}(\mathrm{g}=2.03)$ 및 CPPs $(\mathrm{g}=0.77)$ 는 큰 정도의 효과크기로 유의하게 증가하여 후두마사지가 후두근의 이완 및 후두의 위치를 낮추어 성대의 내전을 도움으로써 MTD 환 자의 음질을 개선시키는 데 효과가 있음을 알 수 있다. 다만 F0-high와 같이 음도를 높이는 기전에는 후두마사지가 효과

Table 2. The effect sizes of laryngeal massage on MTD

\begin{tabular}{lccr}
$\quad$ Variables & Effect size & $95 \% \mathrm{CI}$ & \multicolumn{1}{c}{$\mathrm{p}$} \\
$\quad$ (assessment) & $(\mathrm{g})$ & $-0.28-0.25$ & 0.912 \\
Voice quality & -0.02 & $-0.85--0.31$ & $<0.001$ \\
$\quad$ Jitter & -0.58 & $-0.69--0.09$ & 0.010 \\
Shimmer & -0.39 & $0.22-0.98$ & 0.002 \\
HNR/NHR & 0.60 & $-0.49-1.94$ & 0.242 \\
F0-high & 0.73 & $-1.67--0.47$ & 0.001 \\
I-low & -1.07 & $1.23-2.83$ & $<0.001$ \\
DSI & 2.03 & $0.01-1.53$ & 0.048 \\
CPPs & 0.77 & $-0.64--0.10$ & 0.007 \\
Articulation & -0.37 & $-1.17--0.26$ & 0.002 \\
F1 & -0.71 & $-1.31--0.28$ & 0.002 \\
F2 & -0.80 & $-0.08-0.33$ & 0.242 \\
F1 slope & 0.12 & $0.23-0.50$ & $<0.001$ \\
F2 slope & 0.37 & $-0.33-0.03$ & 0.094 \\
Total & -0.15 & &
\end{tabular}

$\mathrm{CI}$, confidence interval; HNR, harmonic to noise ratio; NHR, noise to harmonic ratio; F0-high, high F0; I-low, low intensity; DSI, dysphonic severity index; CPP, cepstral peak prominence; F1 and F2, first and second form
가 없다는 결과가 도출되었는데, 이는 본 연구에 포함된 논문 들이 상후두근을 이완시키고 후두를 아래로 내리는데 초점 을 맞춘 $\mathrm{MCT}$ 를 대부분 적용하였기 때문으로 보인다. MCT 만 적용한 경우와 상후두근뿐 아니라 윤상갑상근의 이완을 목적으로 $\mathrm{MCT}+\mathrm{CVM}$ 을 함께 적용한 경우를 비교한 연구[3] 를 보면 $\mathrm{MCT}$ 에 비해 두 기법을 함께 적용한 환자군에서 음 질이 더 향상되었고 윤상갑상근의 이완으로 음도범위가 확장 될 수 있다. 즉 MTD 환자의 음질을 개선하고 음역대를 확장 하기 위해서는 후두근을 포함한 후두근 주변의 보다 넓은 범 위 마사지를 실시하는 것이 좀 더 바람직할 것으로 보인다.

조음을 분석한 논문들도 후두마사지가 조음에 미치는 효 과의 결과가 일관되지 않았다. 그러나 본 연구를 통해 개별 연 구들을 종합적으로 분석해보면, F1 ( $\mathrm{g}=-0.71)$ 과 F2 ( $\mathrm{g}=-0.80)$ 는 큰 정도의 효과크기로 유의하게 감소하였고, F2 slope ( $\mathrm{g}=$ 0.37)은 중간 정도의 효과크기로 유의하게 증가하였다.

$\mathrm{MTD}$ 는 후두와 조음기관에 관여하는 근육들의 긴장을 동 반한다. 후두의 긴장과 조임은 설골의 움직임을 제한하고 혀 와 턱의 움직임을 감소시켜 후두의 위치를 상승시키고 인두 강의 길이를 짧게 하여 인두강의 면적을 좁힌다[7]. 이로 인 해 발화 시 포먼트 주파수(formant frequency)가 상승한다. MTD 환자에게 적용한 후두마사지는 후두를 낮추고 성도의 길이를 증가시켜 결과적으로 첫 번째와 두 번째 포먼트 주파 수(F1, F2)를 낮추고, 성도의 운동성을 원활하게 하여 구강조 음기관의 움직임을 향상시키며, 턱, 혀, 후두근 간의 관계를 원활하게 하여 이중모음 산출 시 F1 slope과 F2 slope을 증 가시킬 수 있다[7]. 본 연구에서도 후두마사지가 후두의 위치

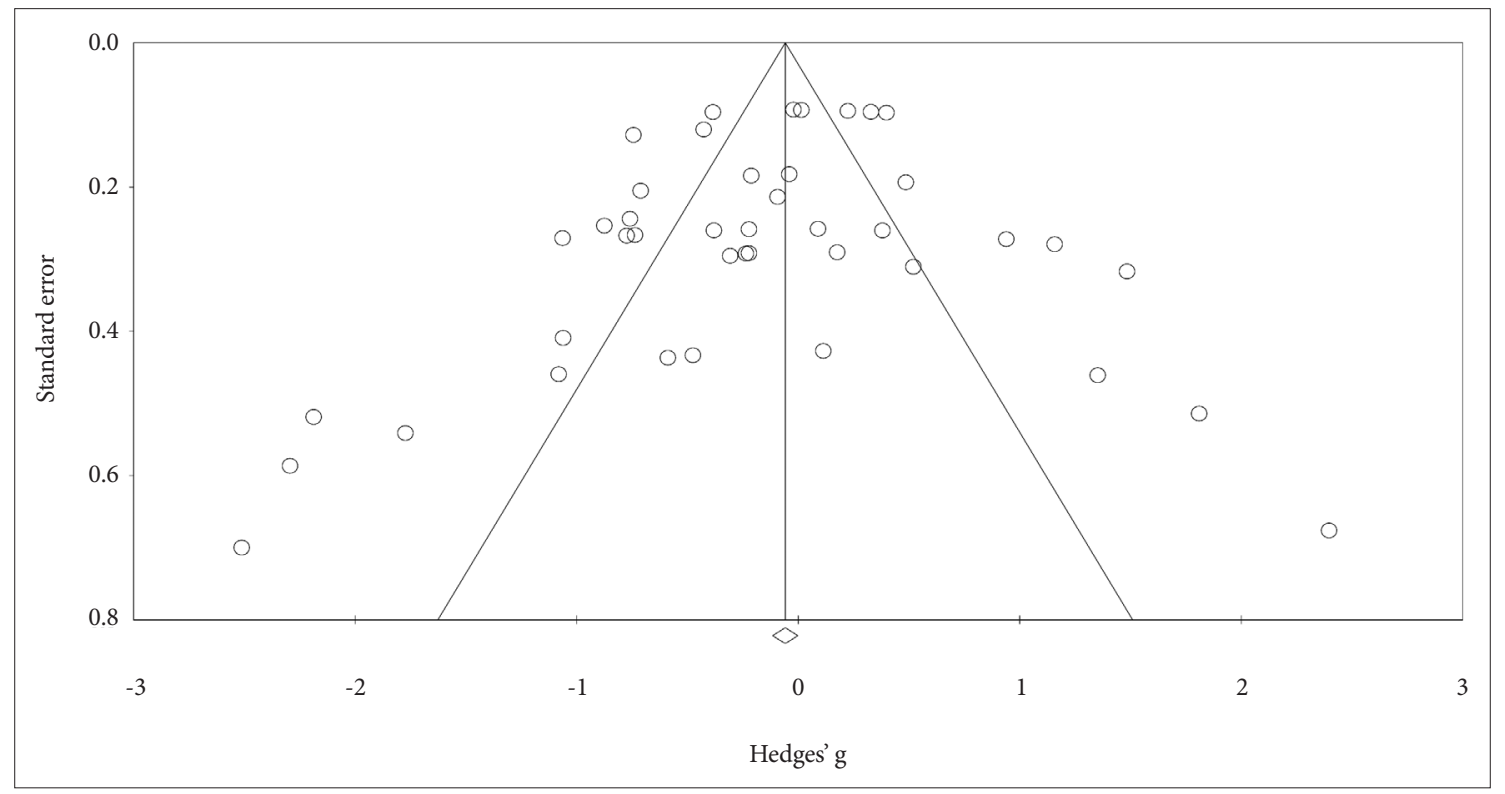

Fig. 5. Funnel plot of precision by Hedges' g. 
를 낮춤으로 F1과 F2가 감소하였고, 조음기관과 성도의 운동 기능을 향상시켜 F2 slope이 증가하였음을 종합적 분석을 통 해 알 수 있었다. 다만 F1 slope은 통계적으로 유의한 효과가 없었는데, 이는 분석한 연구와 대상자의 수가 많지 않음에서 기인한 것으로 보인다.

$\mathrm{MTD}$ 로 인해 후두와 후두 주변의 근육들이 과도하게 긴장 되면 후두의 위치가 상승하고 성대의 길이 조절 기능이 방해 를 받는다. 또한 성도의 길이가 짧아지면서 조음기관의 운동 성이 저하된다. 이로 인해 성대는 긴장하게 되고 발성 시 성대 진동 메커니즘이 원활하지 못해 음질이 저하되며, 음역대가 감 소한다. 그리고 짧아진 성도의 길이와 좁아진 성도, 저하된 조 음기관 메커니즘으로 인해 조음 또한 영향을 받는다. 후두마 사지는 이렇게 과도하게 긴장된 후두와 후두 주변근을 이완 시켜 후두를 적절한 해부학적 위치에 위치시키고 성대가 보다 규칙적으로 진동할 수 있게 하며, 성대의 길이 조절 능력도 향 상시켜 음질이 개선될 뿐 아니라 조음기관의 운동성을 원활 하게 하여 조음 능력도 향상시킨다는 것을 본 메타분석을 통 해 확인할 수 있었다.

메타분석은 다양한 개별 연구들의 결과를 계량적인 방식 으로 종합하여 분석한다. 이를 통해 도출된 종합적 결과는 임 상에서 의사결정을 하는 데 타당한 근거자료로 유용하게 사 용될 수 있다. 본 연구를 통해 후두마사지는 MTD 환자의 음 질과 조음 능력을 향상시키는 데 효과가 있음이 입증되었기에 이를 임상에서 활용하는 근거로 사용할 수 있을 것이다.

본 연구의 제한점으로는 MTD 환자를 대상으로 후두마사 지의 효과를 분석한 RCT 연구가 상대적으로 적어 실험군과 대조군을 통한 효과크기의 동질성 검정과 효과크기를 보다 확증적으로 일반화하기에는 제한이 있다. 또한 본 연구는 후 두마사지의 효과를 단기적인 측면에서 살펴본 논문을 선정하 였기에 후두마사지의 장기적인 효과는 살펴볼 수 없었다. 따 라서 실제 임상에서 MTD 환자에게 후두마사지를 장기적으 로 실시할 때의 효과를 검증하기 위한 다양한 측면의 시도와 $\mathrm{RCT}$ 연구가 지속적으로 이루어질 필요가 있다. 더불어 다른 음성장애군에게 후두마사지를 실시하였을 때의 효과도 종합 적으로 살펴본다면 임상적 근거에 입각한 음성치료를 실시하 는 데 도움이 될 것이다.

\section{결 론}

본 연구는 후두마사지가 MTD 환자에게 음질과 조음에 유 의한 효과가 있는지를 체계적 문헌고찰을 통해 선정된 10편 의 논문을 대상자, 중재 방법, 측정 과제에 따라 14 편으로 구 분하여 메타분석을 실시하였다. 그 결과, 후두마사지는 MTD
환자의 긴장된 후두와 그 주변근을 이완시켜 후두의 위치를 낮추고 성대의 진동과 길이 조절 능력을 향상시켜 음질 개선 과 음역대 확장을 돕고, 조음 능력도 향상시킨다는 것을 알 수 있었다. 이에 본 연구는 MTD 환자의 음성과 조음 산출 메커니즘을 강화하기 위해 후두마사지가 효과적이라는 것을 밝혔으며, 이러한 음성치료를 임상현장에서 적극 활용할 수 있는 근거를 제시하였다.

중심 단어: 메타분석; 후두마사지; 근긴장성 발성장애; 음질; 조음.

\section{Supplementary Materials}

The online-only Data Supplement is available with this article at https://doi.org/10.22469/jkslp.2021.32.2.64.

Acknowledgments

I would like to thank Professor Seung-Jin Lee, Hallym University, for his help in testing the reliability of this study.

Conflicts of Interest

The author has no financial conflicts of interest.

\section{REFERENCES}

1. Aghadoost S, Jalaie S, Khatoonabadi AR, Dabirmoghaddam P, Khoddami SM. A study of vocal facilitating techniques compared to manual circumlaryngeal therapy in teachers with muscle tension dysphonia. J Voice 2020;34(6):963.e11-963.e21.

2. Dehqan A, Scherer RC. Positive effects of manual circumlaryngeal therapy in the treatment of muscle tension dysphonia (MTD): Long term treatment outcomes. J Voice 2019;33(6):866-71.

3. Dehqan A, Ballard KJ. An evaluation of short-term treatment outcomes of cricothyroid visor maneuver: A proof-of-concept pilot study. J Voice 2021;35(2):330.el-330.e7.

4. Rezaee Rad A, Moradi N, Shater Zadeh Yazdi MJ, Soltani M, Mehravar M, Latifi SM. Efficacy of manual circumlaryngeal therapy in patients with muscle tension dysphonia. Shiraz E-Med J 2018;19(7): e64478.

5. Roy N, Nissen SL, Dromey C, Sapir S. Articulatory changes in muscle tension dysphonia: Evidence of vowel space expansion following manual circumlaryngeal therapy. J Commun Disord 2009;42(2):124-35.

6. Ribeiro VV, Pedrosa V, Silverio KCA, Behlau M. Laryngeal manual therapies for behavioral dysphonia: A systematic review and metaanalysis. J Voice 2018;32(5):553-63.

7. Dromey C, Nissen SL, Roy N, Merrill RM. Articulatory changes following treatment of muscle tension dysphonia: Preliminary acoustic evidence. J Speech Lang Hear Res 2008;51(1):196-208.

8. Mathieson L, Hirani SP, Epstein R, Baken RJ, Wood G, Rubin JS. Laryngeal manual therapy: A preliminary study to examine its treatment effects in the management of muscle tension dysphonia. J Voice 2009; 23(3):353-66

9. Laukkanen AM, Leppänen K, Tyrmi J, Vilkman E. Immediate effects of 'voice massage' treatment on the speaking voice of healthy subjects. Folia Phoniatr Logop 2005;57(3):163-72.

10. Tomlinson CA, Archer KR. Manual therapy and exercise to improve outcomes in patients with muscle tension dysphonia: A case series. Phys Ther 2015;95(1):117-28.

11. Van Lierde KM, De Ley S, Clement G, De Bodt M, Van Cauwenberge P. Outcome of laryngeal manual therapy in four Dutch adults with persistent moderate-to-severe vocal hyperfunction: A pilot study. J 
Voice 2000;18(4):467-74.

12. de Oliveira Lemos I, da Cunha Pereira G, Druck SantAnna G, Cassol $M$. Effects of a voice therapy program for patients with muscle tension dysphonia. Folia Phoniatr Logop 2017;69(5-6):239-45.

13. Borenstein M, Hedges LV, Higgins JP, Rothstein HR. When does it make sense to perform a meta-analysis? In: Borenstein M, Hedges LV, Higgins JP, Rothstein HR, editors. Introduction to Meta-Analysis. Chichester: John Wiley \& Sons;2009. p.357-64.

14. Anhaia TC, Klahr PDS, Ourique AAB, Gadenz CD, Fernandes RA, Spagnol PE, et al. Effects of two interventions in teachers with voice complaints. Audiol Commun Res 2014;19(2):186-93.

15. Roy N, Ferguson NA. Formant frequency changes following manual circumlaryngeal therapy for functional dysphonia: Evidence of laryngeal lowering? J Med Speech Lang Pathol 2001;9(3):169-75.

16. Van Lierde KM, De Bodt M, Dhaeseleer E, Wuyts F, Claeys S. The treatment of muscle tension dysphonia: A comparison of two treat- ment techniques by means of an objective multiparameter approach. J Voice 2010;24(3):294-301.

17. Slim K, Nini E, Forestier D, Kwiatkowski F, Panis Y, Chipponi J. Methodological index for non-randomized studies (minors): Development and validation of a new instrument. ANZ J Surg 2003;73(9): 712-6.

18. Wan X, Wang W, Liu J, Tong T. Estimating the sample mean and standard deviation from the sample size, median, range and/or interquartile range. BMC Med Res Methodol 2014;14:135.

19. Lipsey MW, Wilson DB. Practical meta-analysis. Thousand Oaks: Sage Publications;2001.

20. Deeks JJ, Higgins JP, Altman DG. Analysing data and undertaking meta-analyses. In: Higgins JPT, Thomas J, Chandler J, Cumpston M, Li T, Page MJ, Welch VA, editors. Cochrane Handbook for Systematic Reviews of Interventions. Chichester: John Wiley \& Sons;2019. p.241-84. 
Supplementary Table 1. Descriptive summary of included studies [1-5,7,8,14-16]

\begin{tabular}{|c|c|c|c|c|c|c|c|c|c|c|c|c|}
\hline \multirow{2}{*}{ Author (yr) } & \multirow{2}{*}{ Study design } & \multirow{2}{*}{ Diagnosis } & \multicolumn{2}{|c|}{ Experimental group } & \multicolumn{2}{|c|}{ Control group } & \multicolumn{3}{|c|}{ Therapy } & \multirow{2}{*}{ Speech sample } & \multicolumn{2}{|c|}{ Outcomes (assessment) } \\
\hline & & & $\mathrm{n}(\mathrm{M} / \mathrm{F})$ & Age (yr) & $\mathrm{n}(\mathrm{M} / \mathrm{F})$ & Age (yr) & Type & Session & $\overline{\text { Duration }}$ & & Voice quality & Articulation \\
\hline Aghadoost et al. (2020) & One group & Primary MTD & $8(0 / 8)$ & 39.8 & - & - & MCT & 10 & 45 & Sustained /a/ & Jitter, F0-high, I-low, DSI & \\
\hline Anhaia et al. (2014) & One group & Hyperunctional dysphonia & $20(0 / 20)$ & 38 & - & - & MCT & 1 & 20 & Sustained /a/ & Jitter, shimmer & \\
\hline Dehqan and Scherer (2019) & One group & Primary MTD & $28(0 / 28)$ & 32.1 & - & - & MCT & 15 & 30 & Sustained /a/ & Jitter, shimmer, NHR & $\mathrm{F} 1$ \\
\hline Dehqan and Ballard (2021) 1 & RCT & Primary MTD & $30(0 / 30)$ & 28.7 & $28(0 / 28)$ & 28.6 & $\mathrm{MCT}$ & 1 & 30 & Sustained /a/ & Jitter, shimmer, HNR, CPPs & \\
\hline Dehqan and Ballard (2021) 2 & $\mathrm{RCT}$ & Primary MTD & $30(0 / 30)$ & 28.9 & $28(0 / 28)$ & 28.6 & $\mathrm{MCT}+\mathrm{CVM}$ & 1 & 30 & Sustained /a/ & Jitter, shimmer, HNR, CPPs & \\
\hline Dromey et al. (2008) 1 & RCT & Primary MTD & $110(0 / 110)$ & 46.12 & - & - & MCT & 1 & - & /ai/ in sentence & - & F1 slope, F2 slope \\
\hline Dromey et al. (2008) 2 & RCT & Primary MTD & $110(0 / 110)$ & 46.12 & - & - & MCT & 1 & - & /ei/ in sentence & - & F1 slope, F2 slope \\
\hline Mathieson et al. (2009) 1 & One group & Primary MTD & $10(2 / 8)$ & 30.3 & - & - & LMT & 1 & $5-10$ & Sustained /a/ & Jitter, shimmer, NHR & $\mathrm{F} 1, \mathrm{~F} 2$ \\
\hline Mathieson et al. (2009) 2 & One group & Primary MTD & $10(2 / 8)$ & 30.3 & - & - & LMT & 1 & $5-10$ & Sentence & NHR & - \\
\hline Rad et al. (2018) 1 & One group & Primary MTD & $8(8 / 0)$ & 37.6 & - & - & MCT & 1 & - & Sustained /a/ & Jitter, shimmer, HNR & $\mathrm{F} 1$ \\
\hline Rad et al. (2018) 2 & One group & Primary MTD & $12(0 / 12)$ & 34.1 & & & MCT & 1 & - & Sustained /a/ & Jitter, shimmer, HNR & $\mathrm{F} 1$ \\
\hline Roy and Ferguson (2001) & One group & Hyperfunctional dysphonia & $75(4 / 71)$ & 46.1 & - & - & MCT & 1 & - & Sustained /a/ & - & $\mathrm{F} 1, \mathrm{~F} 2$ \\
\hline Roy et al. (2009) & One group & Primary MTD & $111(0 / 111)$ & 46.12 & - & - & MCT & 1 & - & Sustained /a/ & - & $\mathrm{F} 1, \mathrm{~F} 2$ \\
\hline Van Lierde et al. (2010) & Crossover & Primary MTD & $10(6 / 4)$ & 58 & $10(6 / 4)$ & 58 & MCT & 1 & - & Sentence & Jitter, F0-high, I-low, DSI & \\
\hline
\end{tabular}

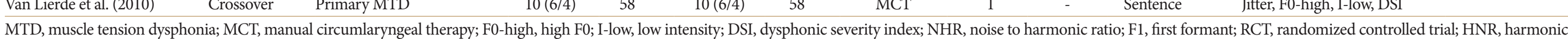
to noise ratio; CPP, cepstral peak prominence; CVM, cricovisor maneuver; LMT, laryngeal manual therapy; F2, second formant 